\title{
Elemech Exhaust System
}

\author{
Jagdish Tanaji Pawar \\ NBN Sinhgad School of Engineering, Pune, India
}

\begin{abstract}
Now a days Air Pollution grows rapidly that effect faces human beings. Elemech exhaust system is support for go green. These device useful for reducing NOx and Carbons from car exhaust with the help of Electric energy and Mechanical devices. Elemech is very compact in size it will be fit in any car.
\end{abstract}

Keywords: Elemech; venturi; Ammonia; Electrons

\section{Introduction}

As the name indicates this device is a combination of Electric energy and Mechanical device. The Exhaust from cars are contains carbons, hydrocarbons, oxides of nitrogen. These gases are harmful for living things on earth. So we have to control the toxic gases and convert them into Nontoxic. Already we have a Catalytic converter Exhaust system available but there prices are high. So with Elemech exhaust system we can control pollution with low price.

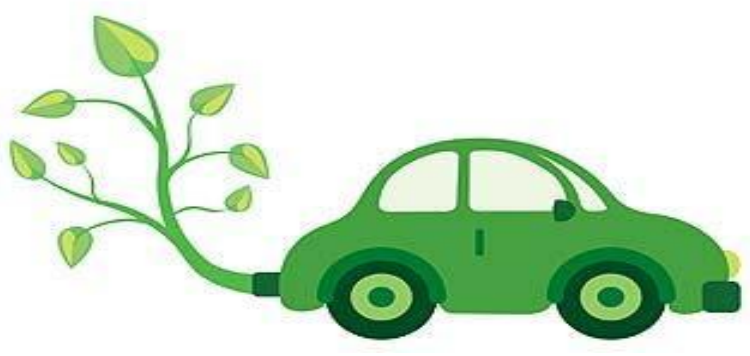

Figure 1: pollution free car.

\section{Electrical System}

These system useful for converting carbon atom into solid form for that purpose below Instruments uses:

- Copper coil

- 9volt batteries

- Controlling switch

- Electrical wires

The process of electrical system is given below:

- Electrons play important role in this system.

- Electrons having -ve charge \& carbon having +ve charge.

- When current flows through the coil it induces magnetic field.

- Then electrons are attracted towards the carbon atoms.

- Then reaction happens and carbon turns into powder form.

- Carbon powder is then removed from exhaust which is done by $\mathrm{NH} 3$ solution with the help of pump spray.

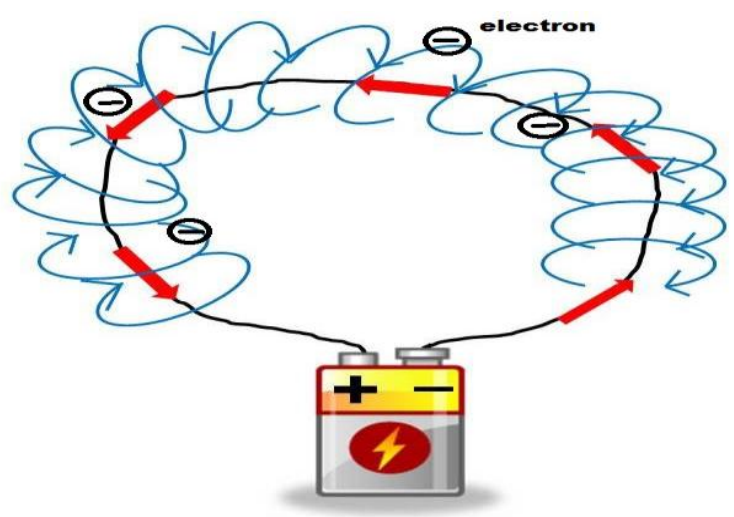

Figure 2: Electrons flowing through wire.

The battery is causing electrons to flow through the wire in the direction of red arrows. This flow of electrons (or electrical current) is creating a magnetic field around the wire, represented by the blue arrows.

\section{Mechanical System}

It includes some components for working of mechanical system.

- Venturi pipe

- $\mathrm{NH} 3$ solution

- Submersible motor

- Injector

- One 9v battery

- Storage tank

\subsection{Venturi}

Venturi design is necessary for reducing the velocity of exhaust gases coming from engine. Venturi is direct connected to the exhaust pipe of car. the flow from exhaust is high venturi help to reduces the velocity of gases by increasing the diversion cone length as compared to conversion cone. It gives some time for carbon and electron reaction.

Also venturi reduce noise level. In that way the shape venturi is important in exhaust system. 


\section{International Journal of Science and Research (IJSR) \\ ISSN (Online): 2319-7064}

Index Copernicus Value (2015): 78.96 | Impact Factor (2015): 6.391

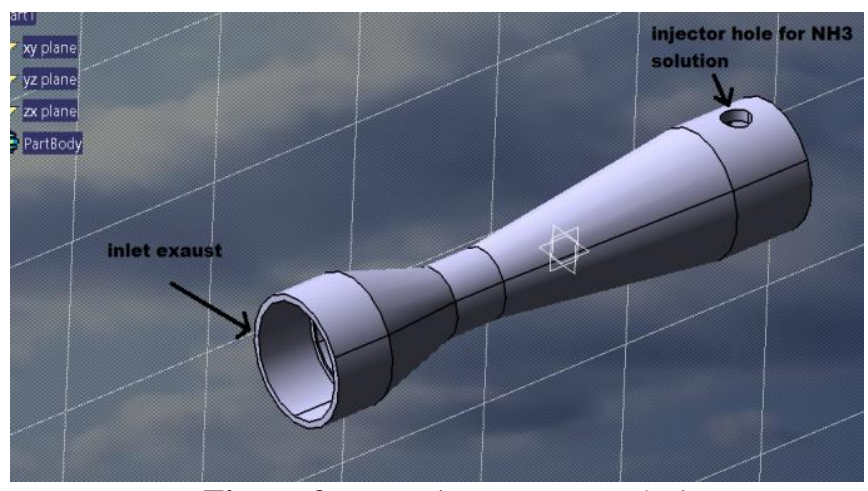

Figure 3: venturi or converter design

\subsection{Injector}

The injector is used for spreading the $\mathrm{NH} 3$ solution into the exhaust gases. Injector atomize the $\mathrm{NH} 3$ and send into the way of gases.

\subsection{Ammonia}

In the selective catalytic reduction (scr) process $\mathrm{NOx}$ react with NH3. Ammonia is injected in gases before the catalyst, but in Elemech exhaust system the ammonia is injected after the electric system. The following are the some reaction happen after the carbon separation process.

- $4 \mathrm{NO}+4 \mathrm{NH} 3+\mathrm{O} 2 \rightarrow 4 \mathrm{~N} 2+6 \mathrm{H} 2 \mathrm{O}$

- $\mathrm{NO}+\mathrm{NO} 2+2 \mathrm{NH} 3 \rightarrow 2 \mathrm{~N} 2+3 \mathrm{H} 2 \mathrm{O}$

- $6 \mathrm{NO} 2+8 \mathrm{NH} 3 \rightarrow 7 \mathrm{~N} 2+12 \mathrm{H} 2 \mathrm{O}$

- $6 \mathrm{NO}+4 \mathrm{NH} 3 \rightarrow 5 \mathrm{~N} 2+6 \mathrm{H} 2 \mathrm{O}$

It has been found that the above reactions are inhibited by water [Willi 1996]. Moisture is always present in diesel exhaust and other flue gases.

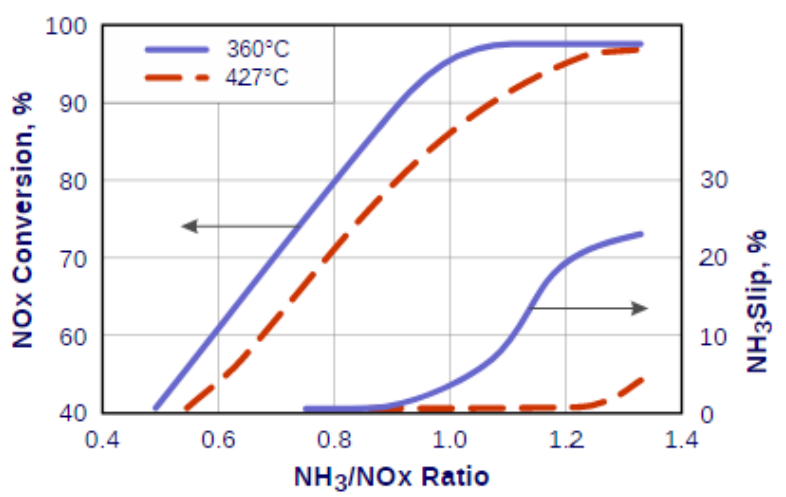

Figure 4: NOx conversion and ammonia slip for different $\mathrm{NH} 3 / \mathrm{NOx}$ ratios

\section{Working of Elemech Exhaust System}

Basically this system is worked on electric as well as mechanical. Diesel cars produces NOx and CO. when temperature of combustion chamber is high upto 2000 degree Oxides of nitrogen is formed these gases are very hazardous For human beings. Also the formation of carbon monoxides in diesel smoke is increase the pollution of air.

When exhaust gases come from engine goes through venturi, where the velocity of gases is reduce this is important because at this stage electrical system works.

The battery supply current to copper coil so electrons flow through coil and create strong magnetic field. Electrons having -ve charge and Carbons having +ve so attraction of electrons towords the carbon atoms is starting. In this reaction carbon atom and electrons get bonded and small powder is form. These carbon powder is washed out by solution of ammonia.

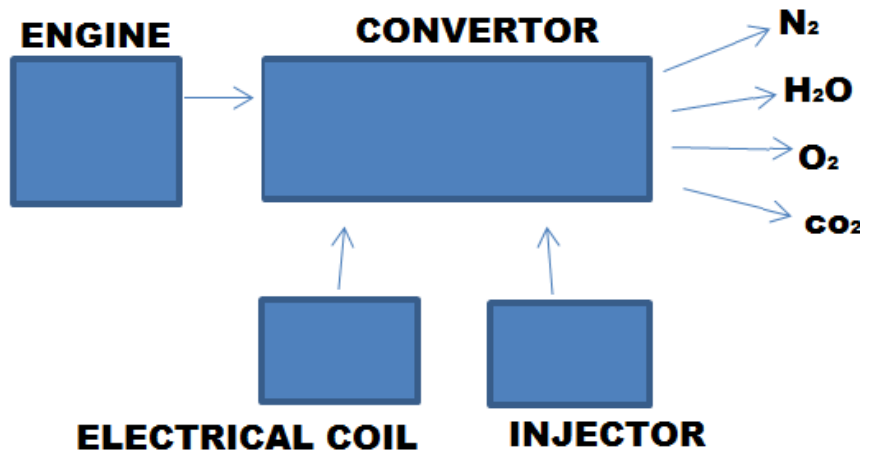

Figure 5: Block diagram of ELEMECH System.

When ammonia is injected into the venturi through hole it come in way of exhaust gases and carbon powder. So it prevent to carbon powder mixed with environment via exhaust gases. Also NH3 is react with NOx and generate some pollution free gases. In that way the Elemech exhaust system works.

\section{References}

[1] Willi, R., B. Roduit, R. Koeppel, A. Wokaun, A. Baiker, 1996. "Selective Reduction of NO by NH3 over Vanadia-Based Commercial Catalyst: Parametric Sensitivity and Kinetic Modeling”, Chem. Eng. Sci., 51 (11), 2897-2902

\section{Author Profile}

Jagdish Tanaji Pawar received the Diploma in Automobile and pursuing B.E. in Mechanical Engineering from NBN Sinhgad School of Engineering. 